\title{
PH-DEPENDENCE OF BACTERIOCHLOROPHYLL FLUORESCENCE IN AQUEOUS EXTRACTS OF PURPLE BACTERIA
}

\author{
by \\ J. B. THOMAS, J. C. GOEDHEER AND J. G. KOMEN* \\ Biophysical Research Group Utrecht-Delft, Utrecht, under the direction of \\ A.J. Kluyver, Delft, and J.M.W. Milatz, Utrecht (The Netherlands)
}

\section{INTRODUCTION}

In a preceding paper ${ }^{1}$ it was confirmed that the bacteriochlorophyll types $B$ 890, $\mathrm{B} 85^{\circ}$ and $\mathrm{B} 800^{2,3}$ are differently affected by low $\mathrm{pH}$. It was furthermore shown that the intensity of this effect depends for each type on the bacterial species in which it occurs. It was concluded that, most probably, the proteinaceous bearer of the pigment predominantly determines the in vivo spectrum. This conclusion is in agreement with a suggestion already made by WASSINK, KATZ AND DORRESTEIN ${ }^{4}$ that the in vivo infrared absorption bands of bacteriochlorophyll might well represent complexes of one and the same pigment with three different proteins.

However, as RABINOWITCH ${ }^{5}$ mentioned and as was remarked in our previous paper, it remains possible that also other phenomena such as the occurrence of several isomeric or tautomeric forms, small differences in chemical composition or in the reduction level of bacteriochlorophyll contribute to the spectrum.

It is well known that porphyrins are highly specific with regard to the $\mathrm{pH}$ dependence of their fluorescence. According to FINK AND HoERBURGER ${ }^{6-8}$, and GoodwIN, KoskI AND OWENS ${ }^{9}$ this property even enables identification of these pigments.

In the living state, fluorescence of the chlorophylls is much weaker than in true solutions. In the colloidal state fluorescence is absent. The fact that the in vivo fluorescence is only weak while, in this state, the chlorophylls are bound to some bearer may suggest that this bearer influences the fluorescence of the pigment. If so, this fluorescence may be affected by inducing changes in the bearer molecule. Since the bearer will be of a proteinaceous nature, such changes may be effectuated by varying the $\mathrm{pH}$. Consequently, if the $\mathrm{pH}$ is varied, a twofold effect on the fluorescence may occur; a direct as well as an indirect effect induced via the bearer molecule. This consideration seems to open up the possibility of getting more insight into the nature of the individual bacteriochlorophyll types.

B 800 and B $85^{\circ}$ transfer absorbed energy to B 890 which fluoresces exclusive$\mathrm{ly}^{2,3}$. It is true that, after elimination of the possibility of energy transfer to B 890 , by heat treatment, B 850 fluorescence can be observed. However, this procedure renders the B 850 type labile so that it cannot be applied here. In consequence it is

* Died I 7 th June, I 955

References $p \cdot 348$. 
only possible to study the influence of $\mathrm{pH}$ on the fluorescence of $\mathrm{B} 850$ and $\mathrm{B} 800$ in an indirect way. The fluorescence yield of these pigment types is also a function of energy transfer to B 89o. If corrections for changes of absorption, or concentration of the molecules, of the various types are applied, and the B 890 fluor escence is not quenched below measurability, it is possible to determine the magnitude of this energy flow as a function of $\mathrm{pH}$. Thus, if each type is irradiated separately, it is possible to study the $\mathrm{pH}$-dependence of fluorescence for B 890 directly, while for both other types this influence may be observable as an effect superimposed on the B 890 fluorescence response to $\mathrm{pH}$.

The present study deals with experiments of this type.

\section{MATERIAL}

Aqueous extracts from the Thiorhodacea Chromatium strain D and the Athiorhodaceae Rhodopseudomonas spheroides and Rhodospirillum rubrum strain 4 were used. The extracts were samples of those described earlier ${ }^{1}$ and used in a concomitant study on $\mathrm{pH}$-induced absorption changes. For details concerning cultivation of the bacteria and preparation of the extracts we may refer to this paper.

\section{METHODS}

Apparaius. The apparatus used for fluorescence measurements is shown in Fig. I. A beam emitted by the incandescent aeroplane lamp $I$ is interrupted by a rotating sector disc $M$ and made parallel by the lens $L_{1}$. It then passes an interference filter $F_{1}$ and is focussed by $\mathrm{L}_{2}$ on the bacterial extract in one of the cuvettes $C$, or on the reference plate $R$, mounted on a movable slide $S$. Part of the fluorescent light is focussed by $L_{3}$ on an infrared sensitive photomultiplier $\mathrm{P}$ which is cooled with liquid air. The modulated photo-current is amplified by $A$ and fed into an a.c. mirror galvanometer $G$. The filters $F_{2}$ and $\mathrm{F}_{3}$ eliminated scattered light. For $F_{2}$ a Kodak Wratten filter 87 was used. Except for a ro-I 5 fold higher concentration, the contents of the $0.5 \mathrm{~cm}$ filter cuvette $F_{3}$ consisted of the same bacterial extract as used in the irradiated cuvettes $C$. In this way the ratio of

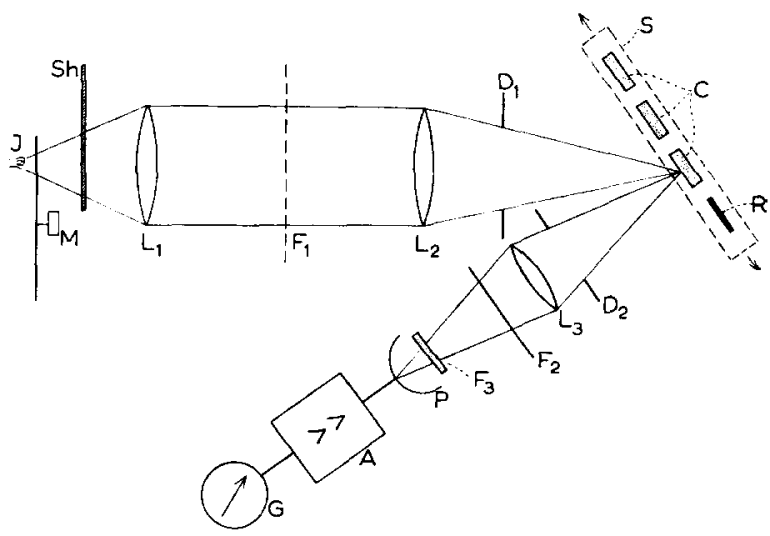

Fig. I. Scheme of the apparatus.

fluorescent light to scattered light entering the photomultiplier was increased for Chromatium and Rhodopseudomonas approximately 9 , I I, and $3^{\circ}$ fold for the wavelengths 880,860 , and $802 \mathrm{~m} \mu$ respectively. The optical axis of the beam of fluorescent light was adjusted nearly perpendicularly to the front side of the cuvettes $C$. Thus, the light reflected by the glass walls of these cuvettes could not enter the lens $\mathrm{L}_{3} . \mathrm{D}_{1}$ and $\mathrm{D}_{2}$ represent diaphragms. Sh indicates a shutter.

Filling of the cuvettes. The three $\mathrm{I} \mathrm{cm}$ cuvettes $\mathrm{C}$, volume $5 \mathrm{ml}$, were filled with $4.5 \mathrm{ml}$ buffer solution of the required $\mathrm{pH}$ each. Then an amount of bacterial extract, constant for each experiment, was added to each cuvette by means of a micropipette. This amount depended on the concentration of the extracts, and varied between 0.1 and $0.2 \mathrm{ml}$. If this was done carefully no mixing occurred. Next, glass covers were placed on the cuvettes. Then, the cuvettes were shaken as quickly as possible until complete mixing was obtained and, at the same time, a stopwatch was started. Immediately afterwards the infrared absorption spectra were measured. Finally, the cuvettes were mounted on the movable slide $S$. The fluorescence measurements were started ro minutes after mixing. They were repeated Io minutes later. After finishing the second series of readings the infrared absorption spectra were redetermined.

Course of the experiment. Ten minutes after mixing the cuvettes were shaken vigorously. The 
extracts of different $\mathrm{pH}$ as well as the reference plate were successively placed in the monochromatic light beam isolated by the GAB interference filter $802 \mathrm{~m} \mu$ and the deflection of the galvanometer $G$ was read. Next the cuvettes were shaken again and the procedure was repeated with the filters 860 and $880 \mathrm{~m} \mu$ respectively. After ro minutes the complete series of measurements was repeated in the same sequence.

\section{EXPERIMENTS NEEDED FOR DETERMINATION OF CORRECTIONS}

In order to correlate the measured photocurrent with the fluorescence intensity, the following corrections were applied. It may be remarked at once that this technique is based on the assumption that fluorescence intensity per particle is proportional to the absorbed amount of light.

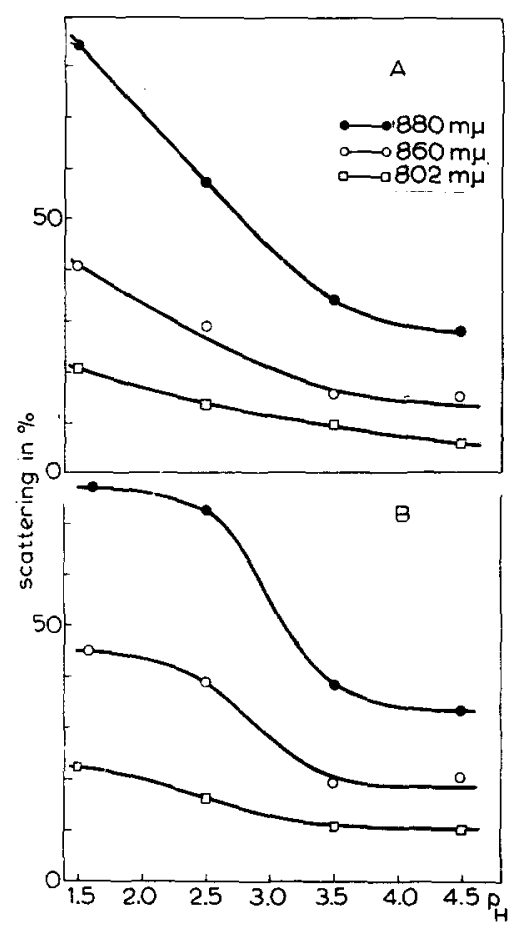

a. Correction for slow fuctuations of the sensibility of the apparatus. After sliding the reference plate into the light beam, the galvanometer deflection was measured after each series of readings. In this way slight fluctuations of the apparatus sensitivity could be eliminated.

b. Correction for scattered light. Owing to $\mathrm{pH}$ variations the turbidity of the extract varied. The correction was approximated as follows. The ratio of the galvanometer deflection shown by the reference plate to that shown by the extract was measured in the presence, ratio $Q_{1}$, and in the absence, ratio $Q_{2}$ of the "bacterial filter" $\mathrm{F}_{3}$. In the latter case the measured light was assumed to be mainly composed of scattered light due to reflection by the cuvette glass walls and scattering by the suspended particles. In the presence of $F_{3}$ the scattered light was absorbed considerably. Thus the deflection of the galvanometer was due to both fluorescence and the remaining part of the scattered light. Since the major part of the fluorescence was also absorbed when using bacterial filters of still higher concentrations, it was impossible to eliminate the scattered light quantitatively. Consequently the fluorescence intensity was calculated according to the formula

$$
I_{\text {fluorescence }}=R_{1}\left(Q_{1}-Q_{2}\right)
$$

in which $R_{1}$ represents the amount of reflection from the reference plate. By varying the amplification the $R_{1}$ values were equalised when measuring $Q_{1}$ and $Q_{2}$.

The fraction of scattered light due to reflections of the glass walls was evaluated by computing the ratio of the galvanometer deflections with the cuvette containing

Fig. 2. $\mathrm{pH}$-dependence of light scattering in an aqueous Chromatium extract. $A$ : Ten minutes after mixing. $B$ : Twenty minutes after mixing.

Fig. 3. Relation between concentration and fluorescence of an aqueous

Chromatium extract.

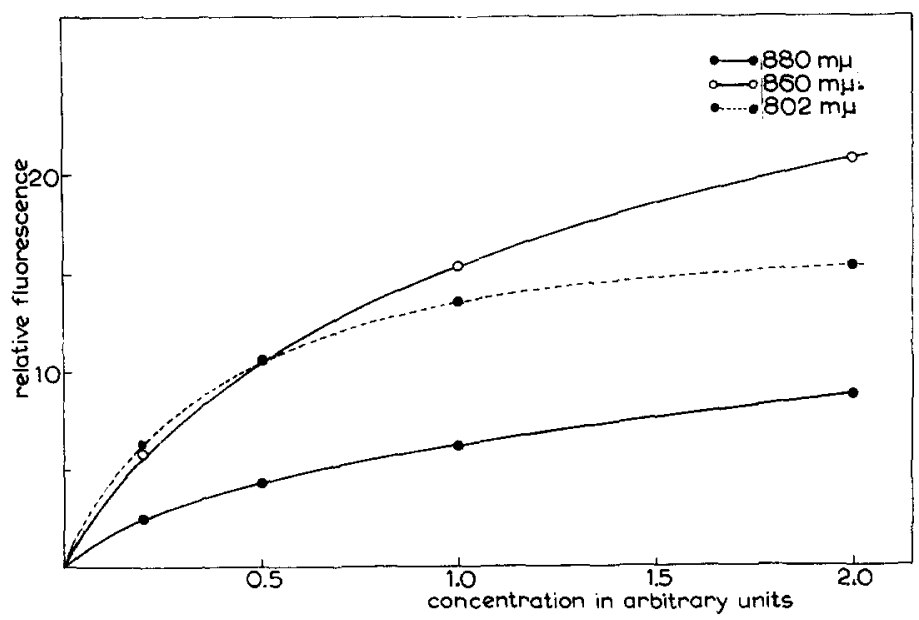

References $p .348$. 
bacterial extract and water respectively. In this way it is possible to calculate the intrinsic scattering variations due to concentration effects. Fig. 2 gives an example for one of the extracts.

c. Absorption correction. Absorption is influenced by slight variations in the pigment concentration of the various samples, and $\mathrm{pH}$-induced spectral fluctuations. Moreover, a change of the distribution of absorption in the cuvettes $C$ will affect the magnitude of the photocurrent owing to altered self-absorption of the fluorescent light and changes of intensity distributions on the photocathode.

In order to obtain an approximate value for this correction the absorption was changed by varying the extract concentration at $\mathrm{pH} 5.0$ and studying the relation between concentration and fluorescence intensity. After applying corrections for scattered light, as outlined above, these values were plotted. A smooth curve was drawn through these points and was used for calibration. An example is presented in Fig. 3 .

\section{RESULTS}

Eight experiments were done with Chromatium extracts. An example of these is shown in Fig. 4. Though the absorption spectra showed marked variations $\left(c .^{1}\right)$, the results

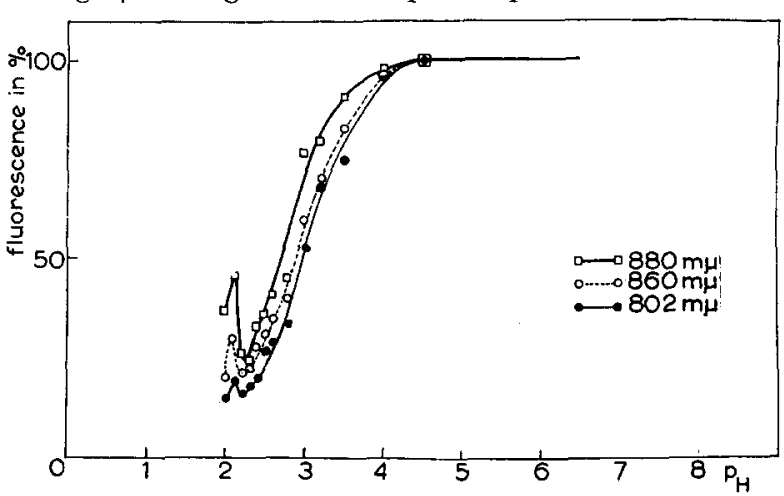

Fig. 4. $\mathrm{pH}$-dependence of fluorescence of an aqueous Chromatium extract. of all fluorescence experiments coincided. The B 890, B 850 and $B 800$ curves run parallel. Though this occurred in all experiments and in the same sequence, the differences were not considered to be significant.

The fluorescence yield is not affected by $\mathrm{pH}$ above 4.5 . This was checked up to $\mathrm{pH}$ II.o. At decreasing $\mathrm{pH}$ this yield drops down to about $20 \%$ at $\mathrm{pH} 2.3-2.5$. On fur-

ther decrease of the $\mathrm{pH}$ either a short rise or a retardation of the decline down to $\mathrm{pH}$ 2.0 was observed. Below this $\mathrm{pH}$ the fluorescence yield declined at a higher rate again.

At $\mathrm{pH} 4.0$ and below the extracts flocculated.

Apart from the fact that fluorescence is equally affected for the three types the situation was different with Rhodospeudomonas extracts. Three experiments were carried out. An example is shown in Fig. 5. The behaviour of these extracts was much more irregular than that of Chromatium preparations. A slow decline of the fluorescence yield from $\mathrm{pH} 4.5$ to $\mathrm{pH}$ r.o is shown. In the other experiments this decline was slower while above $\mathrm{pH} 5.0$ it was absent. However, from all experiments it is

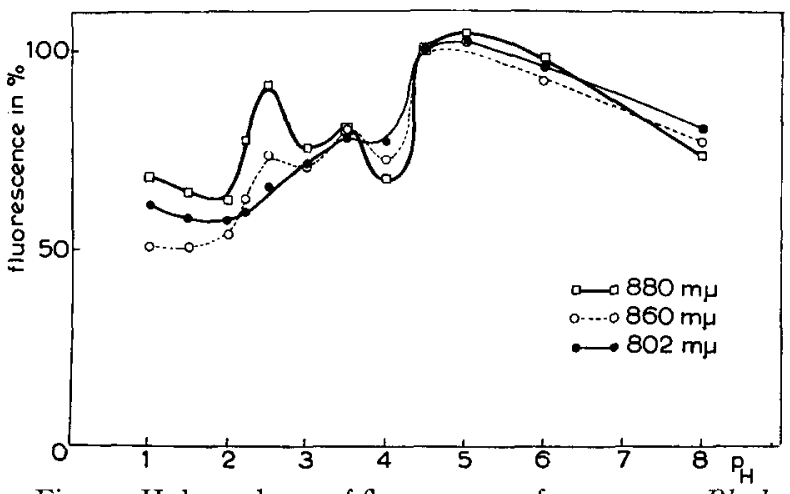

Fig. 5. pH-dependence of fluorescence of an aqueous $R$ hodopseudomonas spheroides extract. obvious that down to $\mathrm{pH}$ I.o no sharp decline occurs. 
The extracts flocculated between $\mathrm{pH} 4.5$ and 3.5 .

With Rhodospirillum rubrum extracts three experiments were carried out yielding identical results. One of these experiments is shown in Fig. 6. It concerns the B 890

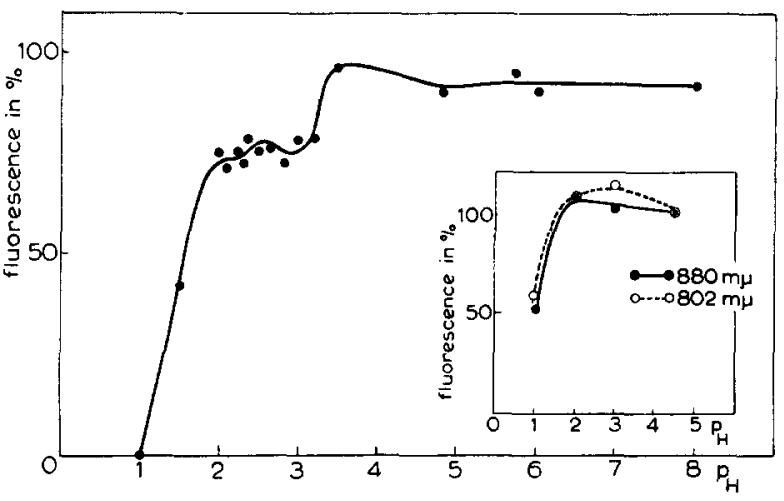

Fig. 6. pH-dependence of fluorescence of an aqueous $R$ hodospirillum rubrum extract. type. The fluorescence drop between $\mathrm{pH} 3.5$ and 3.2 was not observed in all experiments. Most probably, this effect was due to irreproducible and rapid scattering changes caused by flocculation. In the insert an additional experiment, in which the B 800 activity was also studied, is shown. Here, for instance, the fluorescence decline between the mentioned $\mathrm{pH}$ values is absent. In the evaluation of the results this drop is disre-

garded. However, all experiments coincided with regard to the relatively small effect of $\mathrm{pH}$ down to 2.0; below this $\mathrm{pH}$ fluorescence declines sharply. The same is true of the $B 800$ activity.

Flocculation of the extracts occurred between $\mathrm{pH} 4.5$ and 4.0 .

In Table I the results obtained are summarised and compared with $\mathrm{pH}$-induced absorption changes already published ${ }^{1}$.

\section{DISCUSSION}

Comparison of the data from Table I shows that changes in absorption and fluorescence per quantum absorbed are not influenced by flocculation phenomena. Consequently, these alterations of the pigment-bearing particle do not cause noticeable variations of the pigment properties in question. Such a conclusion was also drawn

TABLE I

pH-INDUCED CHANGES IN THE NATURAL BACTERIOCHLOROPHYLL-BEARER COMPLEX

\begin{tabular}{|c|c|c|c|c|c|}
\hline$\underset{I}{\stackrel{I}{\text { Organism }}}$ & $\begin{array}{c}2 \\
\text { Bacterio- } \\
\text { chlorophyll } \\
\text { type } \\
\text { present }\end{array}$ & $\begin{array}{l}{ }^{3} \\
\text { pH at which } \\
\text { fluorescence } \\
\text { stants to } \\
\text { decline }\end{array}$ & $\begin{array}{l}4 \\
\text { pH at which } \\
\text { absorption } \\
\text { starts to } \\
\text { decline }\end{array}$ & $\begin{array}{l}5 \\
\text { Reaction of absorption } \\
\text { to } I-2 \text { hours at pH } 1.0\end{array}$ & $\begin{array}{c}6 \\
\text { Flocculation } \\
\text { pH-range }\end{array}$ \\
\hline \multirow{3}{*}{ Chromatium D } & B 890 & $4 \cdot 5$ & $4 \cdot 5$ & considerably decreased & \multirow{3}{*}{$4.0-<1.0$} \\
\hline & B $85^{\circ}$ & $4 \cdot 5$ & 4.5 & considerably decreased & \\
\hline & B 800 & 4.5 & $4 \cdot 5$ & relatively constant ${ }^{*}$ & \\
\hline \multirow{3}{*}{$\begin{array}{l}\text { Rhodopseudomonas } \\
\text { spheroides }\end{array}$} & В 890 & $<\mathrm{I} . \mathrm{O}$ & $<\mathrm{I} . \mathrm{O}$ & considerably decreased & \multirow{3}{*}{$4 \cdot 5-3 \cdot 5$} \\
\hline & B 850 & $<$ I.o & $<\mathrm{I} . \mathrm{O}$ & relatively constant & \\
\hline & B 800 & $<\mathrm{I} . \mathrm{O}$ & $<$ I.o & considerably decreased & \\
\hline \multirow{2}{*}{ Rhodospirillum rubrum } & B 890 & 2.0 & $<\mathrm{I} . \mathrm{O}$ & slightly decreased & \multirow[b]{2}{*}{$4.6-4.0$} \\
\hline & B 8oo & 2.0 & $3 \cdot 5$ & considerably decreased & \\
\hline
\end{tabular}

* Constancy probably due to a combination of slow decrease of B 800 absorption and simultaneous formation of an $830 \mathrm{~m} \mu$ absorption band, $c .^{1}$.

References p. 348 . 
by KomeN ${ }^{10}$ who did not observe spectral changes in aqueous Chromatium extracts after addition of urea, an agent which strongly denaturates proteins. He suggested that the spectral influence of the bearer molecule is restricted to the pigment-bearer bond or its immediate environment.

The divergence of the flocculation ranges for extracts from the studied strains suggests the presence of different proteins. Nevertheless, Chromatium and Rhodopseudomonas show nearly the same absorption spectrum. In terms of the above suggestion this phenomenon can be explained by the assumption that in the different proteins, or combination of proteins, of these bacteria the same types of pigment-bearer bonds occur. This may be only partly true for Rhodospirillum rubrum where B 850 is absent.

Apart from inducing flocculation which influences neither absorption nor fluorescence, $\mathrm{pH}$ also affects the latter properties provided its value is sufficiently prolonged.

It seems possible, $c .^{10-12}$, to explain the presence of the bacteriochlorophyll types in terms of association phenomena. However, as discussed earlier ${ }^{\mathbf{1}}$, the $\mathrm{pH}$-induced spectral changes of the natural pigment-bearer complex, ct. Table I columns 4 and 5, seem to favor the assumption that some influence from the bearer on the pigment determines the in vivo spectrum. Influence of the bearer on the pigment is probably also demonstrated by the fact that bacteriochlorophyll in the natural state is light-stable while in organic solution it is not. Whether this type of influence, is the same as that which is suggested to be responsible for the determination of the in vivo spectrum remains doubtful.

However, if the effects in question are a function of certain bearer properties it seems plausible to explain the different $\mathrm{pH}$-dependence of absorption and fluorescence in the studied strains in terms of different bearer influences. The relatively large differences of the natural pigment complexes already mentioned might also suggest that the different bacteria contain different bacteriochlorophylls. However, if in connection with these differences, the identity of the absorption spectra of bacterial extracts in organic solvents is considered, the former explanation seems preferable.

This would imply that functional properties of bacteriochlorophyll are also influenced by the natural bearer of this pigment.

In Rhodospirillum rubrum the fluorescence per quantum absorbed is affected at higher $\mathrm{pH}$ than the absorption. This phenomenon might suggest that the fluorescence drop below $\mathrm{pH} 2.0$ is a porphyrin property. In this connection it may be recalled, that the rate of decline of fluorescence in Chromatium increased below the same $\mathrm{pH}$. In Rhodopseudomonas, however, a decrease of the fluorescence yield was not observed down to $\mathrm{pH}$ r.o. Thus it is impossible to establish in this way the fluorescence reaction of the pigment proper. FinK AND HoERBURGER ${ }^{6-8}$ examined the fluorescence dependence on $\mathrm{pH}$ for water-soluble porphyrins. Since, however, bacteriochlorophyll is insoluble in water, the $\mathrm{pH}$ influence could not be studied on the isolated pigment.

From the point of view of information about the nature of the various bacteriochlorophyll types the fluorescence experiments are inconclusive; the observed equality of $\mathrm{pH}$-induced fluorescence changes of the various types occurring in the same species may be due either to a limiting effect of the B 890 reaction or to an equal response to $\mathrm{pH}$ of these types. To answer this question as well as to check the validity of the above considerations further study is needed.

References $p \cdot 348$. 


\title{
SUMMARY
}

The $\mathrm{pH}$-dependence of the bacteriochlorophyll fluorescence in aqueous extracts from Chromatium strain $\mathrm{D}$, Rhodopseudomonas spheroides, and Rhodospirillum rubrum stain 4 was studied.

This dependence varied for the various species.

Within the same species no different fluorescence responses to $\mathrm{pH}$ changes were observed for the various bacteriochlorophyll types.

The results are discussed in connection with those from an earlier study ${ }^{1}$.

\section{REFERENCES}

1 J. B. Thomas, J. C. Goedheer and J. G. Komen, Biochim. Biophys. Acta, 22 (1956) I.

2 L. N. M. Duysens, Nature, I68 (I95I) 548.

3 L. N. M. Duysens, Thesis, Utrecht, (r 9.52 ).

4 E. C. Wassink, E. Katz and R. Dorrestein, Enzymologia, 7 (I939) I 3.

5 E. I. Rabinowitch, Photosynthesis and Related Processes, Vol. II, Part I, Interscience Publ., New York, 195I, p. 704 .

6 H. FinK AND W. Hoerburger, Z. physiol. Chem., 2 I 8 (I933) i 8 I.

7 H. Fink and W. Hoerburger, $Z$. physiol. Chem., 220 (I933) I 23.

8 H. Fink and W. Hoerburger, $Z$. physiol. Chem., 225 (I934) 49.

9 R. H. Goodwin, V. M. Koski and O. v. H. Oewns, Am. J. Botany, 38 (I95I) 629.

${ }_{10} \mathrm{~J} . \mathrm{G}$. Komen, Internal Rept. Biophys. Research Group Utrecht-Delft, M 3609, I952.

11 A. S. Holt and E. E. Jacobs, Am. J. Botany, 4I (I954) 7 Io.

12 E. E. Jacobs, A. E. Vatter and A. S. Holt, Arch. Biochem. Biophys., 53 (I954) 228.

Received February 9th, I956

\section{THE APURINIC ACIDS FROM DEOXYRIBONUCLEIC}

\section{ACID FRACTIONS ${ }^{\star}$}

\author{
by \\ M. E. HODES ${ }^{\star \star}$ AND ERWIN CHARGAFF \\ Cell Chemistry Laboratory, Department of Biochemistry, \\ College of Physicians and Surgeons, Columbia University, New York (U.S.A.)
}

We continue here our studies on the formation, composition and degradation of apurinic acids. It has been proposed to use this designation for the non-dialyzable product of the carefully controlled acid hydrolysis of a deoxyribonucleic acid, in which the removal of the purines is accompanied by neither the loss of nucleic acid phosphorus nor the impairment of the original interpyrimidine ratios ${ }^{1}$. Previous studies from this laboratory have dealt with some of the properties of apurinic acid preparations from calf thymus deoxyribonucleic acid ${ }^{1,2}$, with their behavior as the substrate of pancreatic deoxyribonuclease $\mathrm{s}^{\mathbf{3}, 4}$, with their usefulness as intermediates in the search for trace pyrimidines in deoxypentose nucleic acids ${ }^{1}$, and, finally, with

* This work was supported by research grants from the National Institutes of Health, U.S. Public Health Service, and the Rockefeller Foundation.

${ }_{\star}^{*}$ Postdoctorate Research Fellow, U.S. Public Health Service. Present address, First (Columbia University) Research Service, Goldwater Memorial Hospital, New York 17, N.Y. This report is in part from a dissertation submitted by M. E. HoDEs, in partial fulfilment of the requirements for the degree of Doctor of Philosophy in the Faculty of Pure Science, Columbia University.

References p. 360 . 